$635-11$

\title{
calidades de masas refractarias de cromomagnesita en dependencia de su composición y temperatura
}

\author{
Eigenschaften feuerfester Chrommagnesitmassen in Abhângigkeit von ihrer \\ Zusammensetzung und Brenntemperatur
}

Editoria], Silikattechnik, vol. 8, n. ${ }^{\circ} 2$, pág. 84, Febrero 1957

Experimentos de A. I. Ljudwinski, destinados a conocer que fin más conveniente debe ser elegido para la composición de masa en dependencia de la temperatura, cuando las materias primas, que se determinan en la próxima tabla 1 , sean empleadas en la fabricación de piedras de cromomagnesita.

TABLA N S . 1

Composición quimica de las naterias qutmicas empleadas

\begin{tabular}{|c|c|c|c|c|c|c|c|}
\hline & $\mathrm{StO}_{2}$ & $\mathrm{Al}_{2} \mathrm{O}_{3}$ & $\mathrm{Fe}_{2} \mathrm{O}$ & $\mathrm{CaO}$ & MgO & $\mathrm{Cr}_{2} \mathrm{O}_{3}$ & u. s \\
\hline Cromitakimpersaisk. & 5,88 & 13,19 & 11,76 & 1,04 & 20,85 & 45,8 & 2,18 \\
\hline Magnesita........ & 2,88 & 1,48 & 2,10 & 1,20 & 91,0 & - & 1,34 \\
\hline
\end{tabular}

La cromita-kimpersaisk, que existe en grandes extensiones junto al Don, sería molida en granos de 0,5 hasta $3 \mathrm{~mm}$ de diámetro.

La magnesita Satkinsker, como segundo componente material, se tratará antes en horno giratorio hasta $1600^{\circ} \mathrm{C}$ y se introduce la masa en granos de 0,25 hasta $3 \mathrm{~mm}$ de diámetro. Parte de las fracciones granuladas se combina según la cantidad de materia prima empleada. (Tabla 2).

TAHLA NÚB. 2

Wuestras empleadas y distribucion de particulas

\begin{tabular}{|c|c|c|c|c|c|}
\hline \multicolumn{2}{|c|}{$\begin{array}{l}\text { COMPONENTES } \\
\text { EMPLEADOS }\end{array}$} & \multicolumn{2}{|c|}{$\begin{array}{c}\text { TAMAÑO DE LOS GRANOS } \\
\text { DE CROMLIA }\end{array}$} & \multicolumn{2}{|c|}{$\begin{array}{l}\text { TAMANOO DE LOS GRANOS } \\
\text { JE MAGKESITA }\end{array}$} \\
\hline Cromita & $\begin{array}{c}\text { Magnesila } \\
\% \neq \\
\ldots \ldots \ldots \ldots\end{array}$ & $\begin{array}{c}0,5 \text { hasla } 3 \text { min } \\
\%\end{array}$ & $\begin{array}{l}0,5 \\
\%\end{array}$ & $\begin{array}{c}0,25 \text { hag } 1 \mathrm{~s} 8 \mathrm{~mm} \\
\%\end{array}$ & $\begin{array}{l}\text { Paso por tamiz de } \\
4,900 \mathrm{mallas} / \mathrm{cm}^{2} \\
\%\end{array}$ \\
\hline 80 & 20 & 50 & 30 & - & 20 \\
\hline 70 & 30 & 50 & 20 & 6 & 24 \\
\hline 60 & 40 & 45 & 15 & 8 & 32 \\
\hline 50 & 50 & 40 & 10 & 15 & 35 \\
\hline 40 & 60 & 30 & 10 & 25 & 35 \\
\hline 30 & 70 & 20 & 10 & 35 & 35 \\
\hline 20 & 80 & 5 & 15 & 45 & 30 \\
\hline
\end{tabular}


Las diferentes masas se mezclarán en dilución dei 3,3 hasta el $4 \%$ en lejía de sulfito con una concentración de $1,19 \mathrm{~g} / \mathrm{cm}^{3}$, de igual modo del $\mathrm{x}$ al $\mathrm{I}, 2 \%$ de lejía de sulfito sobre una masa seca del $100 \%$. Se fabricarán con una presión $1000 \mathrm{~kg} / \mathrm{cm}^{3}$ cuerpos cilíndricos de $36,3 \mathrm{~mm}$ de diámetro y $50 \mathrm{~mm}$ de altura, asi como cuerpos de forma cúbica, para contrastaeión, de $65 \mathrm{~mm}$ de arista, así como cuerpos normales, y serán todos tratados en horno industrial. Los valores encontrados en el examen de estos cuerpos difieren sólo aecidentalmente unos de otros. Se tratará una serie a 1500,1600 y $1750^{\circ} \mathrm{C}$, respectivamente. La duración de calefacción, ascendió a $7^{8}$ horas; el tiempo de conservación a $8 \mathrm{~h}, \mathrm{y}$ la duración de refrigeración de 72 a 86 horas.

Después del tratamiento se examinarán todos los cuerpos en relación a ta disminución, porosidad, peso, estabilidad al fuego, estabilidad de la temperatura correspondiente a las Normas GOST para materiales refractarios. Una vez vista la estabilidad de la temperatura se desistirá de una calefacción de $850^{\circ} \mathrm{C}$ por el método de GOST; en este caso, calentamos sobre $1000^{\circ} \mathrm{C}$ y después enfriamos con agua de 15 a $20^{\circ} \mathrm{C}$.

Después del análisis podemos conocer: la disminución de las masas examinadas en la parte de magnesita, disminuyendo la porosidad en este caso. EI peso crece al aumentar la temperatura, e influirá este crecimiento, pero su influencia es poco importante. Parte de magnesita produce un buen efecto sobre la estabitidad mecánica con temperatura de $1500^{\circ} \mathrm{C}$.

Con 1500 " C, fas piedras de $30 \%$ de cromita y $70 \%$ de magnesita tenían la mayor estabilidad de peso al fuego; con $1600^{\circ} \mathrm{C}$, las de $60 \%$ de cromo y $40 \%$ de magnesita; y con $1750^{\circ} \mathrm{C}$, las de $60 \%$ de cromita v $40 \%$ de magnesita. En todos los casos, la estabilidad de la temperatura fué igual aproximadamente.

El empleo de las masas debe ajustarse a la temperatura de uso prevista en jéenticas condiciones. Los materiales mencionados contienen, para una temperatura de $1600^{\circ} \mathrm{C}$, las mismas partes de cromita y magnesita; para $1750^{\circ} \mathrm{C}$, la parte de cromita debe encontrarse con 70 basta $80 \%$. 